$\Phi=\Phi$

\title{
Household human development index and measurement: a study of Muslims in Kashmir
}

\author{
Asif Ahmad Naik ${ }^{1 *}$, E. Selvarajan ${ }^{2}$ \\ ${ }^{1}$ PhD Research Scholar Department of Economics Annamalai University \\ ${ }^{2}$ Professor of Economics Department of Economics Annamalai University \\ *Corresponding author E-mail: naikasif@hotmail.co.uk
}

\begin{abstract}
Sustainable development of Muslims in India is one of the major challenges before the planners and policy makers particularly in the State of Jammu and Kashmir at a phase when India has registered growth in all spheres of life. Yet, the major question that still remains unanswered is as how far have the Muslims of Jammu and Kashmir benefited from the fruits of development (Naik 2013, 143-49). The answer particularly depends upon the ways through which development is conceived and measured. The development strategies must aim at the integration of the people of the region of Kashmir with rest of the country (Naik 2015, 614-616). The present paper attempts to measure human development of the Muslim households of Kashmir regions. Further, it attempts to examine the interrelationship among various indicators of HDI and will depict the extent of achievements of the surveyed villages ranking them as per their human development index adopted. It also suggests policy measures to improve HDI in the study region.
\end{abstract}

Keywords: Diversified Development Region (DDR); Undiversified Development Region (UDR); Life Expectancy; Education Index; Income Index.

\section{Introduction}

Conceptually the human development index has the three components as per the UNDP's Human Development Index viz., long and healthy life as represented by life expectancy, knowledge as represented by education index consists of expected years of schooling and mean years of schooling, and income index consists of GNP (PPPUS\$) (HDR 2014, 160). Data related to mortality in the surveyed villages has been recorded. Health status, nutritional intake, data related to the educational status of household members including current enrollment, and dropouts were collected by the scholar with the help of an interview schedule. Further, the data were collected on income and consumption expenditure, and other details such as household income sources, expenditure on food and non-food items, indebtedness of the households, gender wise earners, and political participation.

Aggregation and weighting of the components of HDI is one of the most challenging issues since the publication of first UNDP HDR's 1990 (UNDP 1990). For the present study, equal weights have been assigned to the three dimensions with the geometric mean so as to observe the variation of any component on the overall index (OPHI 2011, 6)

\section{Methodology}

The present study is based on the primary data and an interview schedule has been used to conduct the survey at the household level to measure the health indices, education indices and income indices. Further, data on mortality, continuations and dropout data, illiteracy and literacy data, sources of income, consumption expenditure by the surveyed households have also been collected The UNDP methodology 2010 has been adopted to work out the
HDI index at household level in the region of Kashmir. Further six villages from two tehsils from the Shopian district of the Kashmir region have been selected on the bases of overall economic activities and cropping pattern. All the six surveyed villages have been classified into two categories as the Diversified Development Region (DDR) and the Undiversified Development Region (UDR). Accordingly, Durpora, Reban, and Safinagri villages are treated as DD region and Butpora, Gagran, and Killuda as UD region

A $10 \%$ sample has been taken by adopted disproportionate stratified sampling technique and a sample of 126 households has been selected from six villages for the present study.

\section{Objectives of the study}

3.1. To use appropriate human development indicators to measure the development at the household level.

3.2. To workout the village wise HDI of the Muslim households of the surveyed region of district Shopian.

3.3. To trace the interrelationship among the HDI indicators adopted in the study.

3.4. To suggest policies to enhance the HDI of the surveyed regions.

\section{Indicators employed for the present study}

This section gives a detailed description of the indicators employed in the present study. 


\subsection{Life expectancy index}

Life expectancy at birth is used as an indicator for long and healthy life. Being a cross sectional study, the present study has evolved an alternative method for measuring life expectancy at the household level by using proxy indicators. Age wise mortality data of the surveyed households for the last twenty years has been recorded by using an interview schedule. (Hazel Elspeth et al., 2012). It is assumed that household does recall the deaths of household members occurred in the houses over the past two or three decades. Village wise minimum maximum values have been worked out by using the methodology of UNDP's HDR 2010. The minimum values are based on the concept of subsistence. Using the methodology of the UNDP HDR 2010, the life expectancy of the surveyed villages has been worked out and presented in Table 4.1.

\subsection{Education index}

Education index is an aggregate index derived from two indices as mean years of schooling and expected years of schooling as.

\subsubsection{Mean years of schooling}

Average schooling years of those households village wise who are 25 years and above (UNDP's HDR 2010). Mean years of schooling of the households village wise who are 25 and above have been worked out (excluding illiterates) (Harttgen Kenneth 2012 , 4-25). Those surveyed households were included who have attained a certain level of education (Barro and Lee 2010). Educational status of the households has been worked out such as using the following variables: households completed primary, secondary, Hr. secondary, collegiate, multiply the duration of the schooling years by the proportion of population. Mean years of schooling of households village wise has been worked out by using the same methodology. In India, primary level of education consists of 1-6 years, secondary $6-10, \mathrm{Hr}$ secondary $11-12$, collegiate is above 13 years and diploma 1 years.

Schooling is mandatory in Jammu and Kashmir up to the age of 14 (Pandit Nusrat 2013, 63). A maximum value has been calculated by taking the highest qualification of a person of the surveyed households' heads village wise. The minimum value is taking as zero to all villages accordingly UNDP 2014. Following the methodology, mean years of schooling has been worked out (Broo and Lee 2010, Hazel Elspeth 2012, 14-17).

\subsubsection{Expected years of schooling}

Expected years of schooling has been defined as total years of schooling which a child of certain age expects to receive in his or her life time assuming that the probability of his or her being enrolled in school at any particular age is equal to the current enrolment ratio for that age. Hence, expected years of schooling is simply the sum of the enrolment rates of each age group, where the enrolment rate of a certain age is defined as the number of people of that age enrolled in formal schooling divided by the total population of that same age (UNESCO Institute for Statistics 2009; Hazel Elspeth 2012). Age wise enrollment data have been recorded from the surveyed village through interview schedule and the enrollment rates has been worked out as, current enrollment in all stages such as primary, secondary, Hr. secondary and collegiate divided by the total population of the age in the prescribed stage, Minimum maximum goal posts has been worked out in all surveyed villages and following the methodology of UNDP's HDR 2014, expected years of schooling has been calculated for all the surveyed villages village wise. Summing up the mean years of schooling and expected years of schooling and using the methodology adopted by the UNDP HDR's gives the education index, (Table 4.1).

\subsection{Income index}

Income index is the third indicator as adopted by the UNDP $\mathrm{Hu}-$ man Development Report 2014. For the present study, per capita income of the surveyed households has been used as a proxy measure to carry out income index. Income of the surveyed households from: agriculture, business, Income, Government, nonGovernment, livestock and income from others sources to the surveyed households. The minimum maximum goal posts are set according to the highest and lowest value, transformed to log (per capita income) because increases of income at lower levels have then greater impact on the income index. Following the methodology of UNDP HDR 2014, the income index has been worked out (Table 4.1).

It must be noted that the costs of living in different villages are different and villages with high cost of living also provide greater opportunity for a person for higher earnings. This fact minimizes the difference of cost of living among different villages. Further, in calculation of logarithm $(\log )$ for values used in the formula that reduce the influence of higher values. In the case of income, the lowest value in recorded. The maximum values are set at the highest observed value for each indicator in surveyed villages.

Table 4.1: Human Development Index of the Surveyed Villages

\begin{tabular}{|c|c|c|c|c|c|c|}
\hline \multirow[b]{2}{*}{$\begin{array}{l}\text { Sl. } \\
\text { No }\end{array}$} & \multirow[b]{2}{*}{ Villages } & \multicolumn{5}{|c|}{ Human Development Index } \\
\hline & & $\begin{array}{l}\text { Life Expec- } \\
\text { tancy Index }\end{array}$ & $\begin{array}{l}\text { Education } \\
\text { Index }\end{array}$ & Income Index & HDI & Rank \\
\hline 1 & Durpora & 0.421 & 0.622 & 0.500 & 0.519 & 6 \\
\hline 2 & Safinagri & 0.383 & 0.626 & 0.667 & 0.540 & 5 \\
\hline 3 & Reban & 0.427 & 0.637 & 0.750 & 0.580 & 4 \\
\hline 4 & Butpora & 0.460 & 0.655 & 0.855 & 0.639 & 1 \\
\hline 5 & Gagran & 0.455 & 0.637 & 0.707 & 0.582 & 3 \\
\hline 6 & Killuda & 0.443 & 0.679 & 0.692 & 0.593 & 2 \\
\hline
\end{tabular}

Sources: Computed

Table 4.1 portrays the village wise human development index and its indicators such as longevity, knowledge, and income index. The Government of Jammu and Kashmir have taken serious measure to expend the health and education services within the region with upgradation of the basic infrastructure; new hospitals, and creation of new educational institutions, and at the same time new avenues for employment have been generated. Further, to lower down the maternal mortality, neo-natal and post-natal mortalities, welfare oriented programmes has been initiated and both medical, and financial assistances are being provided. However, the region has some serious challenges in the form of terrorism and political insurgency which slows down welfare measures to trickle-down to the targeted groups. Hence, a major section of the society was unable to receive these benefits. In this section, an attempt has been made by the researcher to analyses life expectancy, educational attainment, and income status of the surveyed households of both the regions so as to examine their performances with respect to HDI.

HDI index of the surveyed six villages of the study reveals that village Butpora of the UD region with life expectancy of 0.460 , education index value of 0.655 and an income index value of 0.855 records the highest HDI value of 0.639 and is ranked first among the six surveyed villages. With a HDI value of 0.59 , Village Killuda of the UD region is ranked second among the six surveyed villages of the study area. It has a life expectancy value of 0.443 , education index value of 0.699 , and income index value of 0.592. As far as village Gagran of the UD region is concerned is having an HDI value of 0.582 and is ranked third among the six surveyed villages of the study area. It has a life expectancy value of 0.455 , education index value of 0.637 , and income index value of 0.707 . 
At the next level, the DD regional villages of the study area, village Reban with a HDI value of 0.580 is having the fourth rank as its life expectancy value is 0.427 , education index value of 0.637 , and an income index value of 0.750 . As far as Safinagri village of the DD region is concerned it has a HDI value of 0.540 and is having the fifth ranks among the six surveyed. The life expectancy value of Safinagri is 0.383 education index value of 0.626 , and income index value of 0.667 . Village Durpora is the six HDI ranked village with an HDI value of 0.519 . The life expectancy value of village Durpora is 0.421 , education index value of 0.622 , and income index value of 0.500 .

It could be concluded that accessibility to education, health services, and employment avenues plays a significant role in the formation of human development. The UD regional villages were performed well with higher educational attainments, decent sources of income and easy access to health care services benefited them in achieving the high human development index value than that of the DD regional villages. Therefore, in order to boost the human development of the study region, Governments have to develop and maintain basic services mainly education, health, and accord priorities for generating employment opportunities. This approach alone would help the benefits of development percolate to every section of the economy.

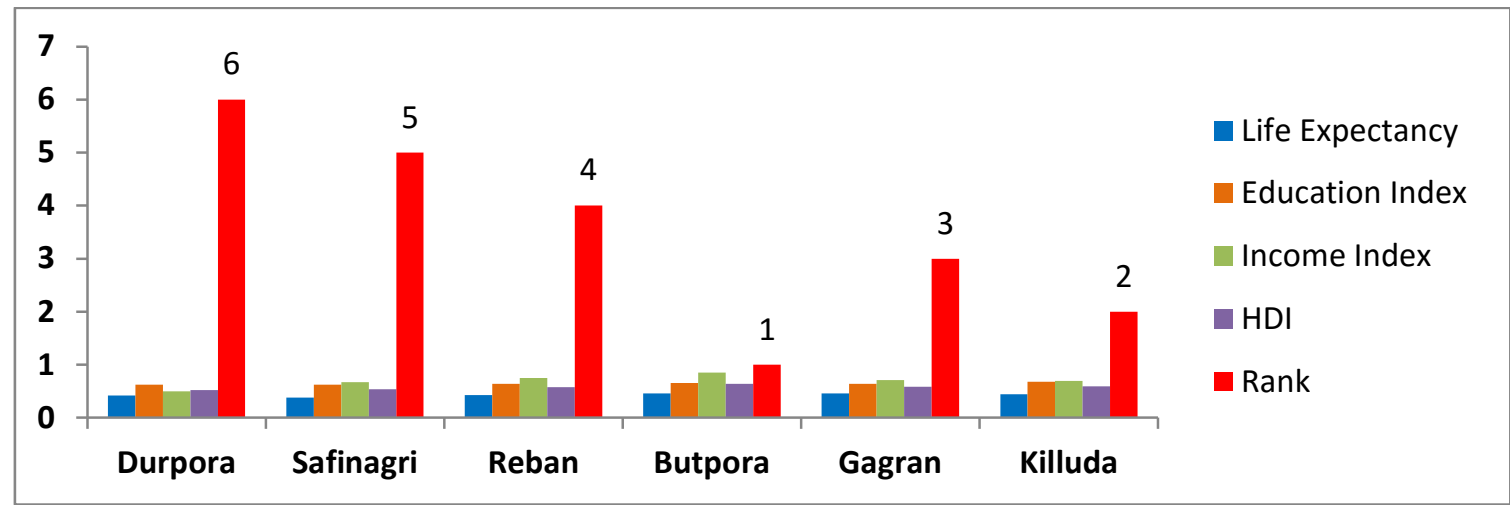

Fig. 1: HDI of the Surveyed Villages.

Table 4.2: Correlation between HDI and Its Indicators

\begin{tabular}{llllll}
\hline & & HDI & Life Expectancy & Education Index & Income Index \\
\hline \multirow{2}{*}{ Spearman's rho } & \multirow{2}{*}{ HDI } & Correlation Coefficient & 1.000 & 0.779 & $0.925 * *$ \\
& Sig. (2-tailed) &. & 0.068 & 0.008 & 0.050 \\
\hline$* *$. Correlation is significant at the 0.01 level (2-tailed). & & & &
\end{tabular}

Correlation is significant at the

Correlation is significant at the 0.05 level (2-tailed).

$\mathrm{N}=6$

Table 4.2 portrays the correlation between HDI and its indicators The HDI indicators consist of Health (life expectancy), education, and income index. Spearman's rho Correlation method has been applied to examine the association between HDI and its indicators The description of correlation results for each pair is given as. The correlation matrix values between HDI and health index (life expectancy) is given. Correlation Coefficient is 0.779 which is close to 1 . This indicates that there is a strong relationship between HDI and (life expectancy). In order to confirm the relationship between HDI and health index (life expectancy), significance value (2- tailed) has been verified as the ' $p$ ' value is $>0.05$ indicates insignificant correlation between the two.

The correlation matrix values between HDI and education correlation co-efficient 'is $=0.925$ which is close to 1 , indicates that there is a strong relationship between HDI and education index. In order to confirm the relationship between HDI and education, significance value (2- tailed) has been verified as the ' $p$ ' value is $<0.05$ indicates that they are significant correlated. The correlation values between HDI and Income index reveals correlation coefficient value of $=0.812$ which is close to 1 indicates that there is a strong relationship between HDI and Income and 'p' value is = 0.05 indicates statistically significance relationship between the two.

It could be concluded that there exists a strong significant correlationship between HDI and education, followed by income. Moderate correlation has been noticed in case of HDI and life Expectancy.

\section{Correlationship among the indicators of HDI}

This section presents correlation results among the HDI indicators
Table 5.1: Correlationship among the Indicator's of HDI

\begin{tabular}{llll}
\hline Variable & $\mathrm{N}$ & $\mathrm{R}$ & Sig. \\
\hline Health index * Education index & 6 & 0.593 & 0.215 \\
Health index * Income index. & 6 & 0.475 & 0.341 \\
Income index* Education index & 6 & 0.571 & 0.346 \\
\hline
\end{tabular}

The HDI dimensions consist of health, education and income index. Correlation method has been applied to find out the relationship between health and education index, health and income index and income index and education index. The description of correlation results for each pair is given in Table 3. The correlation values among the three indices are depicted: The correlation values between health and Education index 0.593, which may be deemed stronger as compared to the correlation values between health and Income 0.475 , which is moderate. However the correlation values between Income and Education (0.571) is strong. These results deviate from the results of health and Income. This reveals that improvement in health and income is more dependent on increase in education. Further, a study conducted by Shah Ismail and Vinod Gosavi 2010, revealed moderate strong relationship between life expectancy and gross enrollment ratio, strong linear relationship between income and adult literacy. However, average relationship between life expectancy and per capita income were observed (Shah Ismail 2010, 14-17).

It could be concluded that better performance of education programmes will uplift other interrelated dimensions such as health; hence special attention may be accorded in this regard so as to enhance human development of the region.

\section{Findings of the Study}

Followings are the main findings of the study 
6.1. Village Butpora of the UD region, with life expectancy of 0.460 , education index value of 0.655 , and an income index value of 0.855 has the highest HDI value of 0.639 and is ranked first.

6.2. With HDI value of 0.593 , Village Killuda of the UD region is ranked second among the six surveyed villages of the study area, regarding a life expectancy value of 0.443 , education index value of 0.699 , and income index value of 0.592 .

6.3. Village Gagran of the UD region is having an HDI value of 0.582 and is ranked third among the six surveyed villages of the study area, having a life expectancy value of 0.455 , education index value of 0.637 , and income index value of 0.707 .

6.4. Village Reban with a HDI value of 0.580 taking the fourth rank and its life expectancy value of the village is 0.427 , with its education index value and income index value are $0.637,0.750$ respectively.

6.5. Safinagri village of the DD region has the HDI value of 0.540 and ranks fifth among the six surveyed villages. The life expectancy value of Safinagri is 0.383 and its education index value is 0.626 . The income index registers the value of 0.667 .

6.6. Village Durpora ranks last in HDI rank with an HDI value of 0.519 . The life expectancy value of village, education index value and income index value were $0.421,0.622$ and 0.500 respectively.

6.7. There exists is a significant correlationship between HDI and education

6.8. There exists is a significant correlation between HDI and education

6.9. Moderate correlation has been noticed between life expectancy and HDI.

6.10. There exists is a strong relationship between health index (life expectancy) and education index

6.11. There exists is a strong relationship between health index (life expectancy) and education index.

6.12. There exists a moderate relationship between Health index (life expectancy) and Income index.

6.13. There exists a strong relationship between Income index and Education index.

6.14. The life expectancy and education revealed strong correlation for the surveyed households. This held that improvement in life expectancy is more dependent on increase in education.

\section{Suggestions}

To achieve an accelerated development process, growth in development has to be processed and followed by progress. The households of villages particularly Durpora and Reban have low level of life expectancy, education index and income requires special attention of the Government in areas of the health, education. Fur ther, upgrading schooling infrastructure, health services, new village level primary health services may be scaled up. In order to achieve cent per cent enrollment ratio, transportation facilities, scholarships, cash transfer with conditions on school attendance, and establishing girl's schools to uplift the female folks in the study district.

Surveyed villages particularly Reban and Safinagri have inadequate access to drinking water facilities resulted health related problems. Although the irrigation department has facilitated some hand pumps in the villages but most of these pumps are outdated, forced inhabitants to consume infected water, hence possess a threat to life and livestock. Therefore, utmost care may be given to resolve these problems. The diversified development region villages are relatively poor as compared to the undiversified development region villages. MGNREGS, NRHM, SARVA SHIKSHA ABHIYAN, JRY, and other employment (Rozgar) schemes may be scaled up to uplift their standard of living.

\section{Conclusion}

The HDI identifies the gap between the current level of achievements and the immense possibilities that can be realized with respect to the human development. In the context of measuring the human development of the surveyed households of the Muslims of Kashmir, moderate human development level has observed. The components of the human development viz. health, education, and income are interrelated and mutually reinforce each other. Further, the empowerment measure mainly for the Muslim women needs to be initiated on priority basis in area of the political participation, employment, and education. Involve the people in the communications and technology will enhance their functioning for more productive purposes with financial incentive in the form of employment, craft schemes, small business units, small scale industries, and other Government schemes will minimize the impact of the political insurgency. All these factors with proper connectivity can lead towards higher HDI and reduction in poverty of the State.

The role of Governments is of immense value in resolving the political insurgency in the region of Kashmir which has been a growing threat to the human development and resources allocation. For the development of the region, it is suggested that the Government sponsored schemes and programmes are all the more warranted with greater focus on addressing the human development issues at the household level.

Acknowledgement

I warmly acknowledge the valuable comments from the anonymous reviewers and Professor R. Elango, Former Dean, Faculty of Arts, Annamalai University) for their fabulous support during this endure.

Abbreviations

DDR: Diversified Development Region

HDR: Human Development Report

HDI: Human Development Index

JRY: Jawahar Rozgar Yojana

MGNREGS: Mahatma Gandhi National Rural Employment Guarantee Scheme

UDR: Undiversified Development Region

UNDP: United Nations Development Programme

\section{References}

[1] UNDP. Human Development Report. Oxford University Press, New York: Oxford 1990.

[2] UNESCO Institute for Statistics. (2009). Duration by Level of Education; United Nations Scientific and Cultural Organization.

[3] Barro R J \& J W Lee (2010). A New Data Set of Educational Attainment in the World, 1950-2010, NBER Working Paper, Cambridge, MA: National Bureau of Economic Research, 2010.

[4] Harttgen Kenneth, \& Stephan Klasen (2010) A Household-Based Human Development Index, Human Development Research Paper, 22, 2010: 4-26. 
[5] Shah Ismail \& Vinod Gosavi (2010). Human Development Index and Human Poverty Index for Indian states, 2005: Multivariate Statistical Analysis of basic indicators. Spring. Department of Statistics School of Economics and Management, Lund University, Sweden 2010, 14-17. (accessed December 1, 2015)

[6] Oxford Poverty \& Human Development Initiative (OPHI). (2011) Oxford Department of International Development, Queen Elizabeth House (QEH), University of Oxford, Research in Progress series 2011:6.

[7] Education Statistic at a Glance Government of India (2011). Ministry of Home Affairs Development, Bureau of Planning, Monitoring and Statistics: New Delhi India, 2011.

[8] Elspeth Hazell, Kar-Fai Gee, \& Andrew Sharpe (2012). The Human Development Index in Canada: Estimates for the Canadian Provinces and Territories, 2000-2011; Sharpe CSLS Research Report, 2012: 14-17. (Accessed January 9, 2016). www.csls.ca.

[9] Pandit Nusrat (2013) Enhancing Education Rate through Capacity Building Programs: Reflections from Jammu and Kashmir. Journal of Business Management and Social Sciences Research (JBM\&SSR) 2, no.7, 2013: 63. (accessed September, 2015)

[10] UNDP. Human Development Report. Oxford University Press, New York: Oxford. 2014.

[11] UNDP. Human Development Report. Oxford University Press, New York: Oxford. 2014:160.

[12] Naik Asif Ahmad \& E Selvarajan (2015). Social inclusion and human development in Jammu and Kashmir, Social Exclusion and Marginalized Groups, Edited by Balamu Murgan, Department of Political Science and Public Administration Annamalai University, Tamil Nadu, India, 2015: 143-150.

[13] Naik Asif Ahmad \& E Selvarajan (2015) Disabled Population: A Temporal Study of Jammu and Kashmir. Journal of Business Management \& Social Sciences Research (JBM\&SSR) 4, no. 11 [November 2015]: 614-616. 